\title{
Effects of Single Dose of Intravenous Dexmedetomidine on Hyperbaric Bupivacaine Spinal Anaesthesia: A Randomized Study
}

\author{
Pradeep Pendyala ${ }^{1}$ \\ ${ }^{1}$ Associate Professor, Department of Anaesthesiology, MediCiti Institute of Medical Sciences, Ghanpur, Medchal, Telangana.
}

\section{Abstract}

Background: The present study is designed to evaluate the effect of intravenous dexmedetomidine on spinal anesthesia with $0.5 \%$ of hyperbaric bupivacaine. Objective: To evaluate the effect of intravenous dexmedetomidine on sensory regression, hemodynamic profile, level of sedation and postoperative analgesia. Subjects and Methods: Sixty patients of American Society of Anaesthesiologists (ASA) physical status I/II patients undergoing elective surgeries under spinal anaesthesia were randomized into two groups of 30 each. Immediately after subarachnoid block with $3 \mathrm{ml}$ of $0.5 \%$ hyperbaric bupivacaine, patients in group D received a loading dose of $0.5 \mu \mathrm{g} / \mathrm{kg}$ of dexmedetomidine intravenously over a period of ten minutes, whereas, patients in group $\mathrm{C}$ received an equivalent quantity of normal saline. Results: Total number of doses of analgesic given as injection diclofenac sodium $75 \mathrm{mg}$ (IM), in Group D was $2 \pm 0.000$ doses and in Group C was $2.85 \pm$ 0.301 doses, which was highly significant as $\mathrm{P}=0.00001<0.01 \quad$ (t-test at $1 \%$ level of significance). Conclusion: Single dose IV dexmedetomidine of $0.5 \mathrm{mcg} / \mathrm{kg}$ prolongs the duration of sensory blockade and analgesia and reduces the requirement of analgesics with lesser incidence of bradycardia and hypotension introperatively as well as postoperatively.

Keywords: Dexmedetomidine, hyperbaric bupivacaine, intrathecal, Ramsay sedation scale, spinal anesthesia.

Corresponding Author: Dr. (Col) Pradeep Pendyala, Associate Professor, Dept of Anaesthesiology, MediCiti Institute of Medical Sciences, Ghanpur, Medchal, Telangana 501401.

Received: January 2019

Accepted: January 2019

\section{Introduction}

Sixty patients were divided into dexmedetomidine group (group D) and control group (group C) of 30 each using computer-generated random list. All the patients are preloaded with $10 \mathrm{ml} / \mathrm{kg}$ of lactated Ringer's solution. Immediately after subarachnoid block with $3 \mathrm{ml}$ of $0.5 \%$ hyperbaric bupivacaine, group D patients receiveid a loading dose of $0.5 \mu \mathrm{g} / \mathrm{kg}$ of dexmedetomidine IV by infusion pump over $10 \mathrm{~min}$ whereas group $\mathrm{C}$ received an equivalent quantity of normal saline as loading dose. Vitals were recorded (heart rate, blood pressure, $\mathrm{SpO} 2$, respiratory rate) immediately after the subarachnoid block and every $5 \mathrm{~min}$ till the end of surgery and for $30 \mathrm{~min}$ after completion of surgery in post-anaesthesia care unit.

\section{Subjects and Methods}

After obtaining approval from the institutional ethics committee and written informed consent from the patients, 60 patients were scheduled for surgeries amenable under under spinal anaesthesia at MediCiti Institute of Medical sciences, Ghanpur, Medchal, Telangana 501401 after meeting the following selection criteria were included in the study
Age between 18-60 and ASA Gr I- II.

Sensory blockade was checked with an alcohol swab and the time taken for the highest level of sensory blockade, twodermatomal regression from the maximum level, and regression to S1 level was noted. Sensory blockade was assessed every $2 \mathrm{~min}$ for the first $10 \mathrm{~min}$ and thereafter every 15 min during surgery and postoperatively. All the durations were calculated considering the time of spinal injection as time 0 .

Motor blockade was assessed by modified Bromage scale (modified Bromage 0, the patient is able to move the hip, knee, and ankle; modified Bromage 1, the patient is unable to move the hip, but is able to move the knee and ankle; modified Bromage 2, the patient is unable to move the hip and knee, but is able to move the ankle; and modified Bromage 3, the patient is unable to move the hip, knee, and ankle). Time taken for motor blockade to reach modified Bromage scale 3 and regression of motor blockade to modified Bromage scale 0 was noted. Motor blockade was assessed every 2 mins before the onset of the surgery and every 15 mins in the post Anaesthesia Care Unit.

The level of sedation was evaluated intraoperatively and postoperatively every 15 min using Ramsay level of sedation scales

\section{Ramsey level of sedation scale}

1. Patient anxious, agitated, or restless 
2. Patient cooperative, Oriented, and tranquil alert

3. Patient responds to commands

4. Asleep, but which brisk response to light glabellar tap or loud auditory stimulus

5. Asleep, sluggish response to light glabellar tap or loud auditory stimulus

6. Asleep, no response

If sensory levels of anesthesia were not equal bilaterally, I used the higher level for the statistical analysis. Patients were discharged from the PACU to the ward after sensory regression to the $\mathrm{S} 1$ segment.

Postoperative pain was assessed using visual analog scale (VAS), every $15 \mathrm{~min}$ until the first analgesic given, and 4 hourly for the next $24 \mathrm{~h}$, rescue analgesia was given in the form of injection diclofenac sodium $75 \mathrm{mg}$ intramuscular (IM) when VAS score was more than 3.

For the purpose of this study, hypotension was systolic BP of $<90 \mathrm{mmHg}$ and if was treated with a bolus administration of $300 \mathrm{ml}$ of lactated Ringer's solution over $10 \mathrm{~min}$ and $6 \mathrm{mg}$ of intravenous ephedrine. Bradycardia was defined as HR $<50$ beats/min, and if persist treated with $0.6 \mathrm{mg}$ of intravenous atropine.

\section{Results}

The demographic data, ASA grade, type of surgery, and duration of surgery were compared between the two groups. The duration of sensory blockade, duration for twodermatomal regression of sensory blockade, and the duration for motor block regression to modified Bromage scale 0 was assessed. The hemodynamic data, complications, and intraoperative atropine/mephentermine/IV fluid requirement in both the groups would be studied. Intraoperative Ramsay sedation scores were studied. Average 24-h consumption of analgesics were studied in the control group as compared to the dexmedetomidine group.

\section{Discussion}

Recent studies have shown the efficacy of both intrathecal and IV dexmedetomidine in prolonging spinal anesthesia. Prolongation of spinal anesthesia after IV dexmedetomidine is by its supra-spinal action at locus ceruleus and dorsal raphe nucleus. There are three subtypes of $\alpha 2$ receptors: A, $\mathrm{B}$, and C. Dexmedetomidine is a more selective $\alpha 2-\mathrm{A}$ receptor agonist than clonidine, with more sedative and analgesic effects. Activation of presynaptic $\alpha 2$-A receptors at locus ceruleus decreases norepinephrine release and causes sedative and hypnotic effects, whereas its effect on descending medullo-spinal noradrenergic pathway results in analgesia by terminating pain signal propagation. At substantia gelatinosa of the spinal cord, it decreases firing in nociceptive neurons and release of substance $\mathrm{P}$, thus producing analgesia. So, dexmedetomidine has a role in modulating pain and inhibiting the transmission and perception of pain. Activation of post-synaptic $\alpha 2-\mathrm{A}$ receptors in CNS results in hypotension and bradycardia by decreasing the sympathetic activity. Activation of postsynaptic $\alpha 2-\mathrm{C}$ receptors in CNS results in anxiolysis, whereas activation of post-synaptic $\alpha 2-\mathrm{B}$ receptors in peripheral vasculature results in transient hypertension. The time at which the first analgesic was requested was $228.58 \pm 6.547 \mathrm{~min}$ in Group D and $161.27 \pm 6.023 \mathrm{~min}$ in Group $\mathrm{C}$ injection diclofenac sodium was used as rescue analgesic. $\mathrm{P}=0.0003<0.01$ (t-test at $1 \%$ level of significance).

Table 1: Age wise distribution of Patients.

\begin{tabular}{|l|l|l|l|}
\hline \multirow{2}{*}{$\begin{array}{l}\text { Age group (in } \\
\text { years) }\end{array}$} & No. of patients & \multirow{2}{*}{ Total } \\
\cline { 2 - 3 } & Group-D & Group-C & \\
\hline $30-39$ & $9(30 \%)$ & $6(20 \%)$ & $12(20 \%)$ \\
\hline $40-49$ & $14(46.7 \%)$ & $13(43.3 \%)$ & $29(48.3 \%)$ \\
\hline $50-59$ & $7(23.3 \%)$ & $9(30 \%)$ & $17(28.3 \%)$ \\
\hline 60 and above & $0(0.0 \%)$ & $2(16.7 \%)$ & $2(3.3 \%)$ \\
\hline Total & 30 & 30 & 60 \\
\hline
\end{tabular}

Table 2: Height wise distribution of Patients

\begin{tabular}{|l|l|l|l|}
\hline \multirow{2}{*}{ Height(C.ms) } & \multicolumn{2}{|l|}{ No. of patients } & \multirow{2}{*}{ Total } \\
\cline { 2 - 3 } & Group-D & Group-C & \\
\hline $140-145$ & $2(6.7 \%)$ & $0(0.0 \%)$ & $2(3.3 \%)$ \\
\hline $145-150$ & $21(70 \%)$ & $13(43.3 \%)$ & $34(56.7 \%)$ \\
\hline $150-155$ & $5(16.7 \%)$ & $17(56.7 \%)$ & $22(36.7 \%)$ \\
\hline $155-160$ & $2(6.7 \%)$ & $0(0.0 \%)$ & $2(3.3 \%)$ \\
\hline Total & 30 & 30 & 60 \\
\hline
\end{tabular}

Table 3: Weight wise distribution of Patients

\begin{tabular}{|l|l|l|l|}
\hline \multirow{2}{*}{$\begin{array}{l}\text { Weight (in } \\
\text { kg) }\end{array}$} & No. of patients & \multirow{2}{*}{ Total } \\
\cline { 2 - 3 } & Group-D & Group-C & \\
\hline $40-44$ & $2(6.7 \%)$ & $0(0.0 \%)$ & $2(3.3 \%)$ \\
\hline $45-49$ & $15(50 \%)$ & $12(40 \%)$ & $27(45 \%)$ \\
\hline $50-54$ & $12(40 \%)$ & $14(46.7 \%)$ & $26(43.3 \%)$ \\
\hline $55-59$ & $1(3.3 \%)$ & $1(3.3 \%)$ & $2(3.3 \%)$ \\
\hline $60-64$ & $0(0.0 \%)$ & $2(6.7 \%)$ & $2(3.3 \%)$ \\
\hline Total & 30 & 30 & 60 \\
\hline
\end{tabular}

Total number of doses of analgesic given as injection diclofenac sodium $75 \mathrm{mg}$ (IM), in Group D was $2 \pm 0.000$ doses and in Group $\mathrm{C}$ was $2.85 \pm 0.301$ doses, which was highly significant as $\mathrm{P}=0.00001<0.01 \quad$ (t-test at $1 \%$ level of significance).

Twenty-four patients out of 30 in Group D achieved sedation score of 3 and in Group C 20 patients achieved a score of 2, rest of them were fully awake.

\section{Discussion}

As sympatholysis is the hallmark feature of central neuraxial blockade, more so after subarachnoid block and dexmedetomidine also leads to significant hypotension and bradycardia, so in our study we kept the timing of administration of dexmedetomidine after the peak of the hemodynamic response due to intrathecal bupivacaine was over, by giving dexmedetomidine infusion $45 \mathrm{~min}$ after intrathecal block with $0.5 \%$ bupivacaine.

In previous studies, dexmedetomidine group had bradycardia compared to the control group, which is similar to the findings of other studies Whizar-Lugo et al. in which higher proportion of patients in the dexmedetomidine group required atropine compared to the control group, as was also reported in other studies Tekin et al. and Hong et al. Contrary to above studies, Al-Mustafa et al. reported no significant difference in atropine requirement between dexmedetomidine and control groups. 
Dexmedetomidine does not have any direct effects on the heart. In the coronary circulation, it causes a dose-dependent increase in coronary vascular resistance and $\mathrm{O} 2$ extraction, but the supply/demand ratio is unaltered. A biphasic cardiovascular response has been described after the administration of dexmedetomidine. A bolus of 0.5 micro $\mathrm{gm} / \mathrm{kg}$ results in a transient increase in BP and a reflex decrease in HR. This initial response is attributed to the direct effects of $\beta$-adrenoceptor stimulation of the vascular smooth muscle. This response can be attenuated by a slow infusion over $10 \mathrm{~min}$, as given in our study, $0.5 \mu \mathrm{g} / \mathrm{kg}$ over $10 \mathrm{~min}$, which resulted in stabilization of the HR and BP 10$15 \%$ below baseline values. In this study, changes in pulse rate, systolic, and diastolic BP were similar in both the groups. The decrease in the HR was more evident in Group D but not statistically significant when compared with Group $\mathrm{C}$, and only two patients required atropine for bradycardia, which was comparable with the control group. The lower HR observed in Group D could be explained by the postsynaptic activation of $\alpha 2$-adrenoceptors in the CNS, which results in a decrease in sympathetic activity and circulating levels of catecholamines. Other studies support the finding that the bradycardia caused by dexmedetomidine is long lasting when used as a premedication drug in these studies dexmedetomidine was given as premedication and in some as continuous infusion throughout the procedure, which lead to hypotension and bradycardia intraoperatively, as well as, postoperatively and which lead to increase drug consumption to overcome these effects, by giving slow infusion and after spinal block when the peak hemodynamic effects of subarachnoid block were already settled I have avoided these complications in my study.

Previous studies have shown that the hypotension caused by dexmedetomidine persists in the intraoperative as well as in the postoperative period. In my patients, there was a fall in mean arterial pressure in Group D as well as in Group C and clinically was not significant. There was no further decrease in the BP after adding intravenous dexmedetomidine to patients with bupivacaine spinal anesthesia. Only two patients in Group D received ephedrine because of fall in systolic BP $<90 \mathrm{mmHg}$, which was statistically not significant and comparable with Group C. Similarly, AlMustafa et al., Tekin et al. and Whizar-Lugo et al. ${ }^{[7]}$ reported no significant difference in mean arterial pressures in the dexmedetomidine group.

The mean duration of two segment regression in Group D and Group C was $137.00 \pm 12.82 \mathrm{~min}$ and $93.76 \pm 6.58 \mathrm{~min}$, respectively [Table 4]. The difference in the duration between the groups is statistically significant. This is consistent with the findings reported by Kaya et al. who concluded that intravenous dexmedetomidine, but not midazolam, prolongs bupivacaine spinal anesthesia. My study also correlates with the study of Al-Mustafa et al. who stated that intravenous dexmedetomidine prolongs bupivacaine spinal analgesia, and also with other two studies. This also correlates with the studies of Hong et al. and Whizar-Lugo et al. Similar observations were also made by Tekin et al.

This table shows the two segment regression time in both the groups. This shows highly significant difference in two regression segment time with $\mathrm{P}=0.00002<0.01$ (t-test at $1 \%$ level of significance).

\begin{tabular}{l}
\hline Table 4: Two segment regression of sensory block \\
\begin{tabular}{|l|l|l|}
\hline Duration (in mins) & Group-D & Group-C \\
\hline Mean & 137 & 93.76 \\
\hline Std. deviation & 12.82 & 6.58 \\
\hline Total & 30 & 30 \\
\hline
\end{tabular}
\end{tabular}

In my study, the time to first request for postoperative analgesic was significantly prolonged $(233.54 \pm 7.50 \mathrm{~min})$ and the $24 \mathrm{~h}$ mean requirement of analgesics was significantly less in the dexmedetomidine group [Tables $5 \&$ 6] compared to the control group that also correlates with the findings reported by Kaya et al. Al-Mustafa et al. and also with Whizar-Lugo et al. Similarly, Hong et al. noticed that postoperative pain intensity was lower and the mean time to first request for postoperative analgesia was longer in the dexmedetomidine group compared to the control group (6.6 vs. $2.1 \mathrm{~h}$ ). Kaya et al. in their study observed that dexmedetomidine increased the time to the first request for postoperative analgesia and decreased the analgesic requirements. Whizar-Lugo et al. In their study noticed that the time to first request for postoperative analgesic in the dexmedetomidine group was $(220 \pm 30 \mathrm{~min})$ significantly prolonged as compared to the control group (150 $\pm 20 \mathrm{~min})$.

Table 5: Time at which first analgesic requested

\begin{tabular}{|l|l|l|}
\hline Duration (in mins) & Group-D & Group-C \\
\hline Mean & 233.54 & 162.71 \\
\hline Std. deviation & 7.50 & 6.03 \\
\hline Total & 30 & 30 \\
\hline
\end{tabular}

This table shows the time at which first analgesic was given to the patients when VAS $>3$ achieved in group D at $233.54 \pm 7.50$ and in group $\mathrm{C}$ at $162.71 \pm 6.03$ with $\mathrm{P}=0.00006<0.01$ ( $\mathrm{t}$-test at $1 \%$ level of significance)

Table 6: Total analgesic consumption

\begin{tabular}{|l|l|l|}
\hline Inj. Diaclofenac sodium & Group-D & Group-C \\
\hline Mean & 2 & 2.9 \\
\hline Std. deviation & 0 & 0.305 \\
\hline Total & 30 & 30 \\
\hline
\end{tabular}

This table shows the total number of doses analgesic in group $\mathrm{D}$ at $2.000 \pm 0.00$ and in group $\mathrm{C}$ at $2.9 \pm 0.305$ with $\mathrm{P}=0.00001<0.01$ which was highly significant (t-test at $1 \%$ level of significance).

Dexmedetomidine does not cause much respiratory depression despite providing good sedation resulting in wide safety margins.19 Sedation scores in Groups D and C were 3 and 2 , respectively [Table 7,6], sedation produced by dexmedetomidine is different from other sedatives as the patient is easily arousable and remains cooperative. The participation of nonrapid eye movement sleep pathways seems to explain why patients who appear to be "deeply asleep" from dexmedetomidine are relatively easily aroused in much the same way as occurs with natural sleep. This type of sedation is termed "cooperative" or "arousable," to distinguish it from the sedation induced by drugs acting on the gamma-aminobutyric system, such as midazolam or propofol, which produce a clouding of consciousness. 
Table 7: Sedation score

\begin{tabular}{|l|l|l|}
\hline Sedation Score & Group-D & Group-C \\
\hline Mean & 2.65 & 2 \\
\hline Std. deviation & 0.39 & 0 \\
\hline Total & 30 & 30 \\
\hline
\end{tabular}

This sedation score achieved in group $\mathrm{D}$ at $2.65 \pm 0.39$ and in group $\mathrm{C}$ at $2 \pm 0.000$ with $\mathrm{P}=0.00000<0.01$ which was highly significant (t-test at $1 \%$ level of significance).

\section{Conclusion}

Single dose IV dexmedetomidine of $0.5 \mathrm{mcg} / \mathrm{kg}$ prolongs the duration of sensory blockade and analgesia and reduces the requirement of analgesics with lesser incidence of bradycardia and hypotension introperatively as well as postoperatively. It produces satisfactory arousable sedation without causing respiratory depression.

\section{References}

1. Kamibayashi T, Maze M. Clinical uses of alpha2 -adrenergic agonists. Anesthesiology. 2000;93:1345-9.[PubMed]

2. Saxena H, Singh S, Ghildiyal S. Low dose intrathecal clonidine with bupivicain improves onset and duration of block with haemodynamic stability. Internet J Anesthesiol. 2009;23:1.
3. Thakur A, Bhardwaj M, Kaur K, Dureja J, Hooda S, Taxak S. Intrathecal clonidine as an adjuvant to hyperbaric bupivacaine in patients undergoing inguinal herniorrhaphy: A randomized doubleblinded study. J Anaesthesiol Clin Pharmacol. 2013;29:66-70. [PMC free article] [PubMed]

4. Sethi BS, Samuel M, Sreevastava D. Efficacy of analgesic effects of low dose intrathecal clonidine as adjuvant to bupivacaine. Indian $\mathbf{J}$ Anaesth. 2007;51:415-9.

5. Eren G, Cukurova Z, Demir G, Hergunsel O, Kozanhan B, Emir NS. Comparison of dexmedetomidine and three different doses of midazolam in preoperative sedation. J Anaesthesiol Clin Pharmacol. 2011;27:367-72. [PMC free article] [PubMed]

6. Nishiyama T, Komatsu K, Hanaoka K. Comparison of hemodynamic and anesthetic effects of hyperbaric bupivacaine and tetracaine in spinal anesthesia. J Anesth. 2003;17:219. [PubMed]

7. Whizar-Lugo V, Gómez-Ramírez IA, Cisneros-Corral R, Gallegos NM. Intravenous dexmedetomidine vs. Intravenous clonidine to prolong bupivacaine spinal anesthesia. A double blind study Anest Méx 2007;19:143-6.

8. Tekin M, Kati I, Tomak Y, Kisli E. Effect of dexmedetomidine IV on the duration of spinal anesthesia with prilocaine: A double-blind, prospective study in adult surgical patients. Curr Ther Res. 2007;68:313-24. [PMC free article] [PubMed]

9. Hong JY, Kim WO, Yoon Y, Choi Y, Kim SH, Kil HK. Effects of intravenous dexmedetomidine on low-dose bupivacaine spinal anaesthesia in elderly patients. Acta Anaesthesiol Scand. 2012;56:3827.[PubMed]

10. Al-Mustafa MM, Badran IZ, Abu-Ali HM, Al-Barazangi BA, Massad IM, Al-Ghanem SM. Intravenous dexmedetomidine prolongs bupivacaine spinal analgesia. Middle East J Anaesthesiol. 2009;20:225-31. [PubMed]

Copyright: () the author(s), publisher. Academia Anesthesiologica International is an Official Publication of "Society for Health Care \& Research Development". It is an open-access article distributed under the terms of the Creative Commons Attribution Non-Commercial License, which permits unrestricted non-commercial use, distribution, and reproduction in any medium, provided the original work is properly cited.

How to cite this article: Pendyala P. Effects of Single Dose of Intravenous Dexmedetomidine on Hyperbaric Bupivacaine Spinal Anaesthesia: A Randomized Study. Acad. Anesthesiol. Int. 2018;3(2):18-21.

DOI: dx.doi.org/10.21276/aan.2018.3.2.4

Source of Support: Nil, Conflict of Interest: None declared. 